\title{
The Role of Anterior Subperichondrial Rasping in Antihelixoplasty of Prominent Ears
}

\author{
AHMED ABD EL-SALAM HAFIZ, M.D. and AHMED MAHER SAMI, M.D. \\ The General Surgery Department, Plastic Surgery Unit, Faculty of Medicine, Cairo University
}

\begin{abstract}
Background: Prominent ears also known as Bat ears is a common ear deformity that can cause emotional problems to the individual involved. Various techniques have been described each with its advantages and disadvantages.

Aim of Work: The aim of otoplasty is reducing the cephaloauricular angle to 15-20 degrees, emphasis on the antihelical fold with a smooth helical rim, concha reduction and lobulopexy. Each ear is analyzed individually regarding its problem areas and the appropriate surgical approach with least possible morbidity is used.
\end{abstract}

Material and Methods: In this study, five patients were operated upon in Kasr Al-Aini Hospital between October 2015 to September 2016. The authors preferred technique for superior crus and antihelix formation was combined anterior subperichondrial rasping through an ventral incision with posterior transverse mattress $3 / 0$ polyester (Ethibond) sutures on round body needle.

Conclusion: This technique is easy, efficient with satisfactory outcome, could be done in most patients of various ages with minimal or absent complication rate.

Key Words: Subperichondrial - Rasping - Antihelixoplasty - Prominent ears.

\section{INTRODUCTION}

A prominent ear is one of the most common ear deformities according to Weerda [1]. According to Wodak, the average distance between helical rim (the upper helix, middle helix and tail of the helix) to the head is from 10-20mm [2]. Also the angle between the mastoid and the helix should not exceed 30 degrees [3]. Components of the bat ear may include one or more abnormalities of the following: Absent antihelix, deep conchal hypertrophy, protrusion of the lobule [4]. Patients with protruding ears show various emotional disorders including depression, lower self-esteem with sociocommunicative problems in school and at home
[5], hence the importance of performing otoplasty before school age around 5-6 years of age. Also at this age, the ear has almost reached its full growth and the cartilage is softer and easier to mold [6]. Non-surgical correction by using appropriate molding devices can achieve good results in neonates. There are many procedures involved in its correction but in general otoplasty is a combination of scoring, incision and suture techniques. The choice of the technique is individualized according to the characteristics of the auricular cartilage and the severity of the ear deformity. In children up to the age of ten, the cartilage is still elastic and easily pliable, thus suturing technique such as described by Mustarde are used alone to achieve a good cosmetic permanent result. In older children and adults due to the relative rigidity of the cartilage other techniques are required including the incisionsuture technique described by Converse, the incision technique described by Stenstrom [7]. In addition, various techniques for cavum reduction, rotation and lobule fixation have been described in the literature. In this paper emphasis is done on superior crus and antihelix formation with review of its literature and the authors preferred method for antihelixoplasty.

\section{PATIENTS AND METHODS}

Five patients were operated upon in Kasr AlAini Hospital, Faculty of Medicine, Cairo University between October 2015 to September 2016 with follow-up for six months for each patient. The patients were four males (80\%) and one female $(20 \%)$ with a mean age of seven years. All patients had prominent ears since birth with a various degree of deformities. No other congenital anomalies were associated with the condition. All patients had in common absent superior crus: Two with completely 
absent antihelix and three with poorly defined antihelix. In association, two had conchal hyper- trophy and one had prominent lobule. Table (1) below showing summary of the cases.

Table (1): Summary of the cases.

\begin{tabular}{llll}
\hline Cases & Age & Sex & Description of the ear deformity \\
\hline 1 & Five & Male & Absent superior crus, absent antihelix, prominent lobule \\
2 & Six & Male & Absent superior crus, poorly defined antihelix \\
3 & Fourteen & Male & Absent superior crus, absent antihelix, conchal hypertrophy \\
4 & Twelve & Male & Absent superior crus, poorly defined antihelix, conchal hypertrophy \\
5 & Five & Female & Absent superior crus, poorly defined antihelix \\
\hline
\end{tabular}

\section{Surgical technique:}

All patients were operated upon under general anesthesia in the operating theater. Marking of the new future superior crus and antihelix was done by methylene blue using a transfixing hypodermic needle. Then diluted adrenaline 1:200 was injected subperichondrial on the ventral surface of the ear limited to the area of the proposed future superior crus and antihelix to achieve hemostasis and aid in hydrodissection. While on the posterior surface, injection was in a subcutaneous plane at the incision line reaching to the free border of the helix. If conchal reduction or conchomastoid suture was to be done then injection was also done in this area reaching to the mastoid fascia. A $5 \mathrm{~mm}$ incision was done in cranial part of the superior crus in a certain fashion so that it was camouflaged by the helix. A thin Dingman periosteal elevator/raspatory with two ends was introduced in the incision with subperichondrial dissection using the broad blunt end limited to the area of the proposed new superior crus and antihelix. The side edge of the thin sharp end of the dissector was used for rasping. This rasping will cause some softening and weakness of the cartilage. No scoring or incision was done in the cartilage maintaining the integrity of the cartilage giving it a smooth elegant shape later on with its molding into the final shape. A posterior auricular incision was done in a curved fashion parallel to the skin crease and dissection was done subcutaneously stopping a few millimeters proximal to the free helical rim to avoid its distortion. Suture material used for the concho-scaphal sutures were white ethibond (polyester) 3/0 on a rounded needle. The small anterior incision is left open allowing for drainage of any collection avoiding hematoma formation with spontaneous wound healing with no scar formation. The postauricular incision was closed with interrupted 5/0 monocryl stitches after excision of any excess postauricular skin allowing a tension free skin closure limiting any future keloid or hypertrophic scar formation. A compression dressing to the ear in the form of cotton or straps soaked with an antibiotic containing preparation was applied in order to stabilize the contour of the newly formed auricle and prevent hematoma formation. The first dressing was maintained for three days and then removed to exclude hematoma formation. After the tenth post-operative days the post auricular skin stitches were removed and a headband was worn for one month. The patient received post-operative antibiotic (penicillin), analgesic and antiedematous measures with sitting position. Fig. (1) below showing the essential steps of the procedure.

\section{RESULTS}

Follow-up was done for six months postoperative showing the final shape of the ear after complete healing and resolved edema with no early complications in the form of hematoma, wound infection, perichondritis, skin or cartilage necrosis or late complications in the form of recurrence, suture material rejection with fistula formation, hyperthesia or parasthesia, hypertrophic scar or keloid and auricular cartilage deformities.

All patients and their parents had a satisfactory cosmetic outcome.

Figs. (2-5) showing sample of two cases operated upon. 

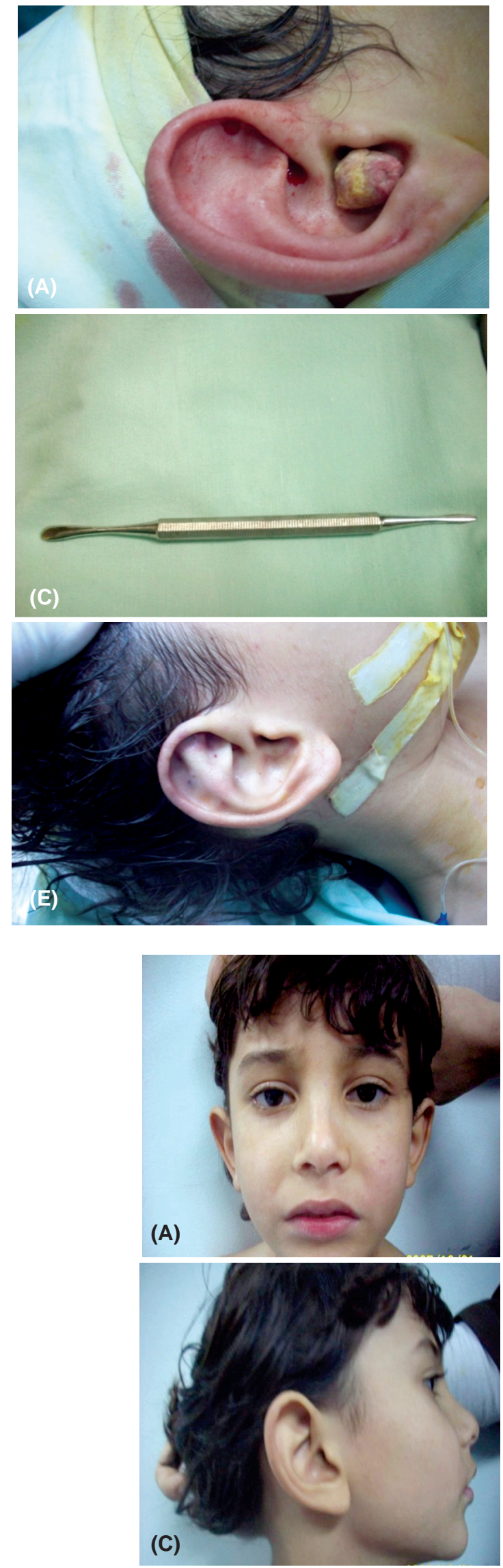
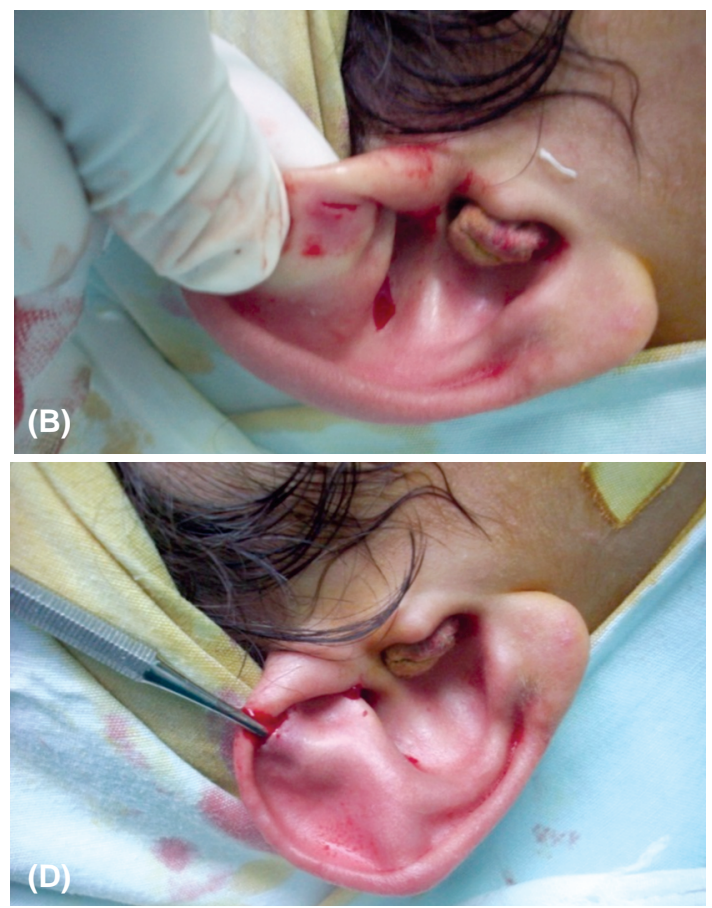

Fig. (1): Intraoperative pictures of a six year old male patient with prominent ears. (A) Right ear with absent superior crus. (B) Site of the incision. (C) The Dingman instrument used. (D) Dissector in the incision with subperichondrial dissection and then rasping. (E) Smooth elegant natural appearing superior cross after conchoscaphal sutures taken.
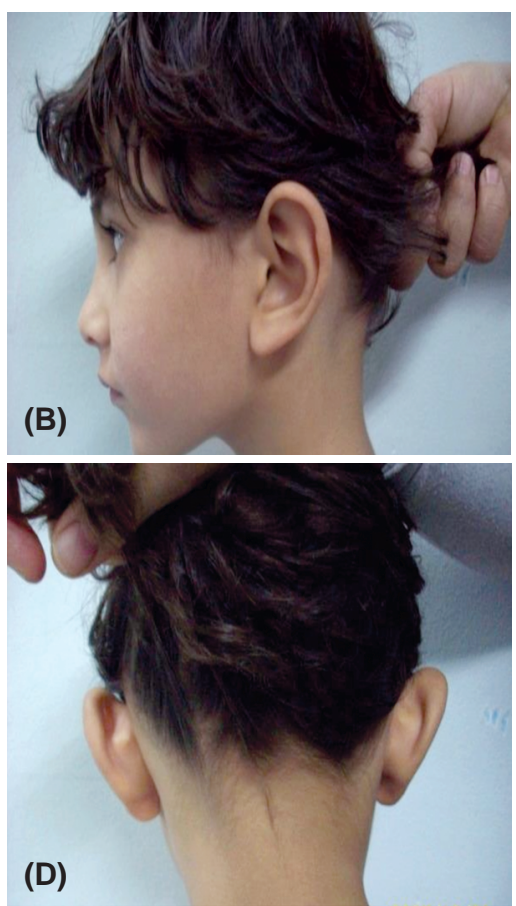

Fig. (2): Preoperative pictures of a six year old male patient with prominent ears (absent superior crus with poorly defined antihelix). Frontal view. (B) Left lateral view. (C) Right lateral view. (D) Occipital view. 

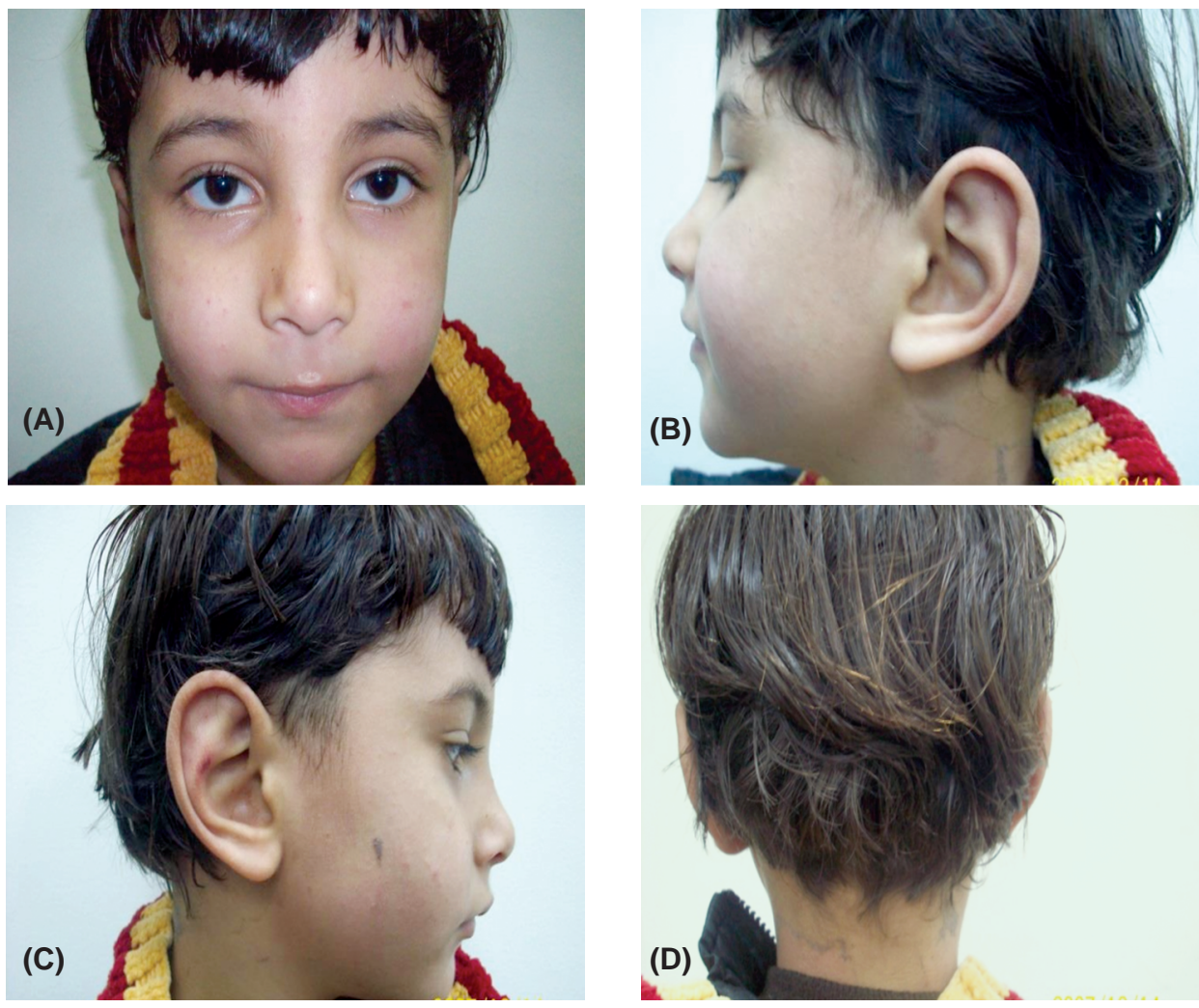

(C)

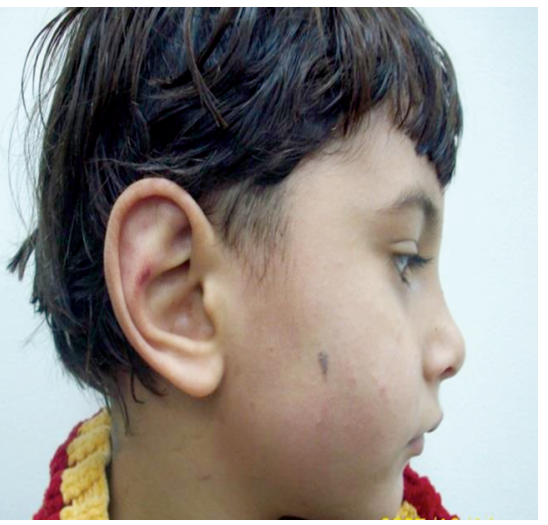

(D)

Fig. (3): Post-operative pictures of the same previous patient after 6 months. (A) Frontal view. (B) Left lateral view (well-formed superior crus) (C) Right lateral view (well-formed superior crus) (D) Occipital view.
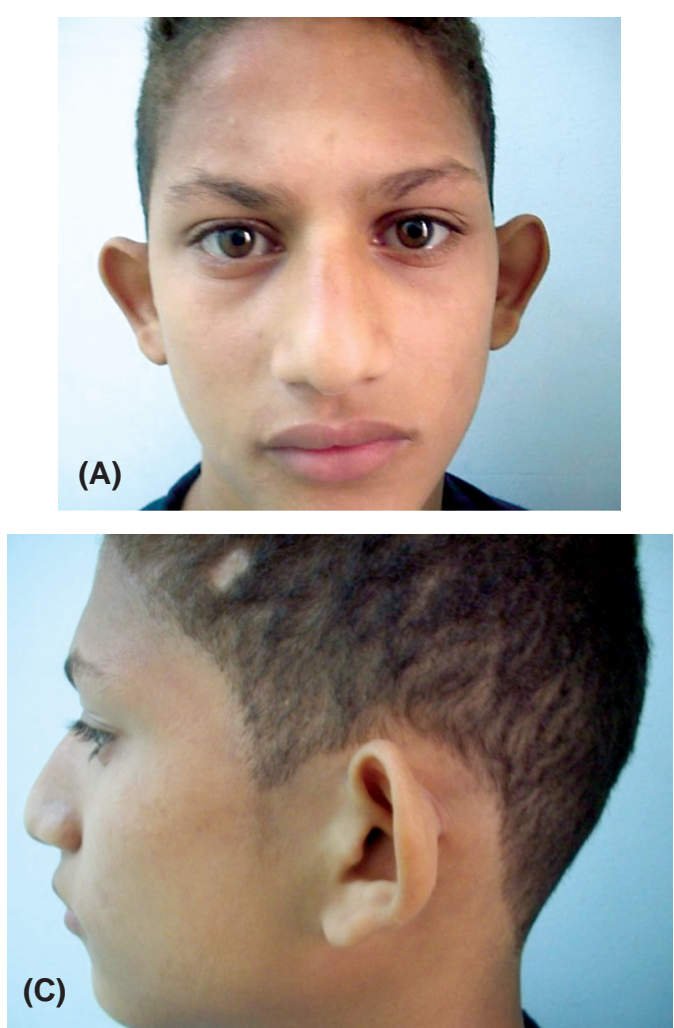
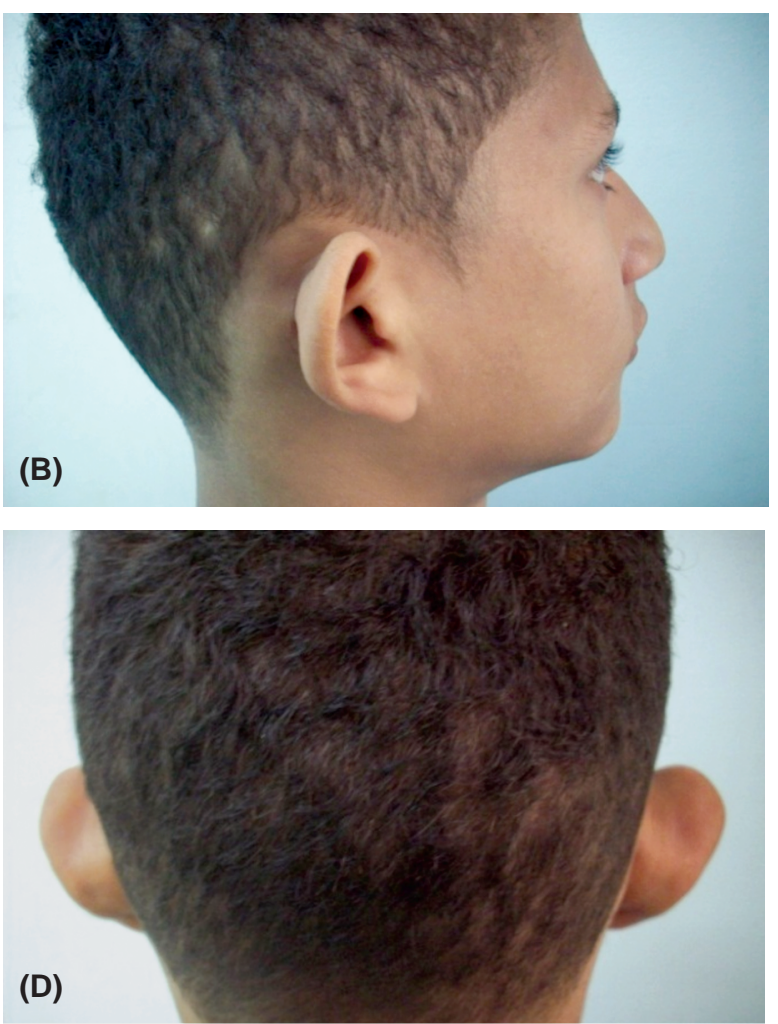

Fig. (4): Pre-operative pictures of a 14 year old male patient with prominent ears (absent superior crus, absent antihelix and conchal hypertrophy). (A) Frontal view. (2) Right lateral view. (3) Left lateral view. (D) Occipital view. 

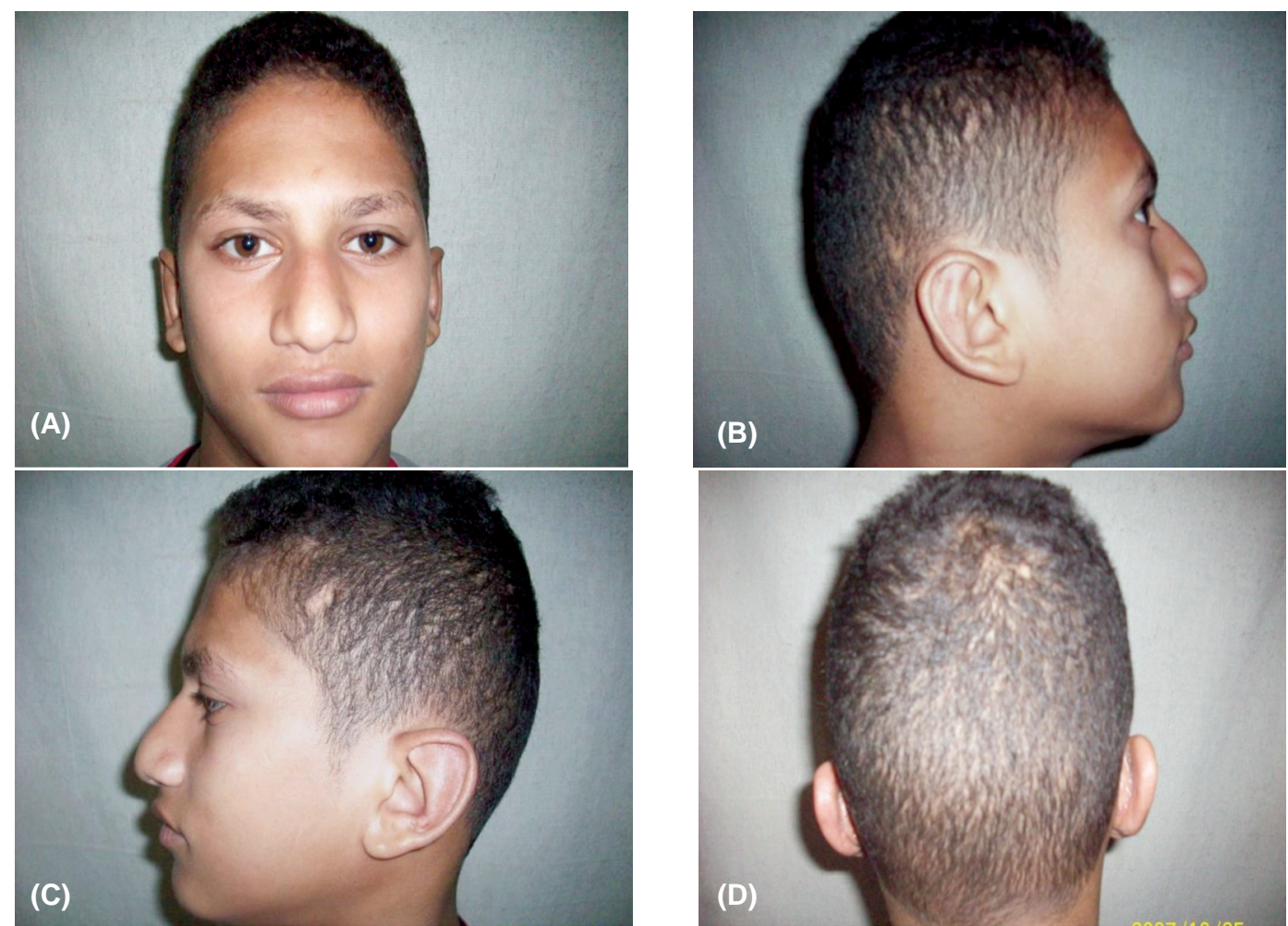

Fig. (5): Post-operative pictures of the previous same patient after 6 months (seated back ears with smooth elegant superior crus and antihelix). (A) Frontal view. (B) Right lateral view. (C) Left lateral view. (D) Occipital view.

\section{DISCUSSION}

It was not before the end of the $19^{\text {th }}$ century when reports for otoplasty techniques were published. In 1845, Dieffenbach described otoplasty of post traumatic prominent ear were he used a conchomastoid suture and excised retroauricular skin [8]. Ely described in 1881 a two-step procedure to correct bilateral bat ears in the form of conchomastoid suture and crescentic resection of cartilage [9]. In 1903, Gersuny observed that skin excision alone is not sufficient to maintain results of an otoplasty due to the elastic memory of the auricular cartilage and skin elasticity [10].

In 1910, Luckett described cartilage-skin excision along the antihelical fold with horizontal mattress sutures to achieve a better scapha [11]. However, Becker in 1952, made an anterior incision along the anti-helical rim in combination with posterior mattress sutures to form a better antihelix [12].

Gibson and Davis discovered that cartilage incised on one side has the ability to wrap to the opposite side [13]. This phenomenon became the start point for the beginning for the techniques used nowadays of incision-scoring in the area of the antihelix. In 1955, Converse described posterior incomplete full thickness cartilage incision including the ventral perichondrium with combined fixation sutures. In 1963, Chongchet described scoring the anterior cartilage of the lateral scapha with a scalpel using a posterior access to form the antihelix while Stenstrom in 1963 used rasping to shape the anterior cartilage by a small posterior access after lifting the ventral perichondrium [14].

In 1963 Mustarde used non absorbable posterior sutures only with no incision or scoring of the cartilage to form the antihelix [15].

Thus to summarize the above mentioned, three methods used alone or in combination are effective in the correction of absent antihelix or superior crus of prominent ears: The incision-suture technique described by Converse, The incision technique described by Stenstrom and the suture technique described by Mustarde. More advanced techniques are described nowadays including the cartilage island flap by pitanguy [16], cartilage thinning using a diamond drill by weerda [17]. However they are more sophisticated requiring more experience and a deep learning curve.

Each of the previous methods of antihelix otoplasty (Antihelixoplasty) has its own advantages and disadvantages and preferably used according 
to the individual circumstances. Generally speaking, excessively deep incision or scoring of the auricular cartilage may result in aesthetically undesirable sharp edges in the antihelix with weakening of the cartilage affecting its stability and integrity. Also trauma to the ventral perichondrium may cause hematoma and chondronecrotic lesions associated with ear deformities. In the authors preferred method, it is sensible to leave the ventral perichondrium intact and avoid cartilage incision or scoring to avoid these possible complications. A 5mm anteriorly placed incision camouflaged by the cranial part of the helical rim was used. This ventrally placed incision is more accessible and easier than the posterior one described by Stenstrom. It was left open for drainage of any fluid avoiding later hematoma formation and completely healed with no scar formation. A Dingman periosteal elevator/ raspatory was used. The broad blunt end was used for subperichondrial dissection, while the narrow sharp end was used for rasping and scratching of the ventral cartilage in the area of the future antihelix and superior crus. Rasping was done to soften the cartilage but at the same time preserving the stability and integrity of the cartilage allowing its posterior warping. Then non absorbable polyester suture was used to fix the newly formed antihelix in its desirable shape. Lobuloplasty, cavum reduction and fixation according to Furnas was done according to the condition. This rasping and scratching will cause some weakness of the cartilage. No scoring or incision was done in the cartilage maintaining the integrity of the cartilage giving it a smooth elegant shape later on with its molding into the final shape. The perichondrium posteriorly is adherent to the underlying cartilage maintaining the blood supply to the cartilage and also the perichondrium aids in holding a good bite of the suture helping to mold the cartilage into the new desirable shape of the superior crus and antihelix. Suture material used for the concho-scaphal and conchomastoid sutures were ethibond (polyester) $3 / 0$ on a rounded needle of whitish color to avoid its show through the thin auricular skin.

To conclude the authors preferred method for antihelix and superior crus formation is by a limited ventral subperichondrial dissection and rasping through an anterior easily accessible incision with preserving intact ventral perichondrium minimizing hematoma formation, future cartilage necrosis and maintaining the integrity of the auricular cartilage allowing an aesthetically pleasing smooth elegant antihelix formation. This is done with a combined posterior transverse mattress sutures to maintain the final shape of the superior crus and antihelix resulting in good results and patient satisfaction.

\section{REFERENCES}

1- Weerda H.: Classification of congenital deformities of the auricle. Facial Plastic Surgery, 5: 385-388, 1998.

2- Wodak E.: On the position and shape of the human auricle. Arch. Klin. Exp. Ohren. Nasen. Kehlkopfheilkd., 188: 331-335, 1967.

3- Farkas L.G.: Anthropometry of the normal and defective ear. Clin. Plast. Surg., 17: 213-218, 1990.

4- Siegert R., Krappen S., Kaesemann L. and Weerda H.: Computer assisted anthropometry of the auricle. Face, 6: 1-6, 1998.

5- Sheerin D., Macleod M. and Kusumakar V.: Psychological adjustment in children with port-wine stains and prominent ears. J. Am. Acad. Child Adolasc. Psychiatry, 34: 16371647, 1995.

6- Gosain A.K. and Recinos R.F.: Otoplasty in children less than four years of age: Surgical technique. J. Craniofac. Surg., 13 (4): 505-509, 2002.

7- Converse J.M., Nigro A., Wilson F.A. and Johnson N.: A technique for surgical correction of lops ears. Plast. Reconstr. Surg., 15: 411, 1995.

8- Dieffenbach J.E.: Die Operative Chirurgie. Leipig: F. A. Brockhaus. 1845.

9- Ely Let: An operation for prominent auricles. Arch. Otolaryngol. 1881; 10: 97 reprinted in Plast. Reconstr. Surg., 42: 582, 1968.

10- Gersuny R.: Uber Einige Kosmetische Operationen. Wien Med. Wochenschr., 53: 2253, 1903.

11- Luckett W.H.: A new operation for prominent ears based on the anatomy of the deformity. Surg. Gynecol. Obstet., 10: 635,1910 .

12- Becker O.J.: Correction of protruding deformed ear. Br. J. Plas. Surg., 5: 187, 1952.

13- Gibson T. and Davis W.: The distortion of autogenous cartilage grafts: Its cause and prevention. Br. J. Plast. Surg., 10: 257, 1958.

14- Stenstrom S.J.: A natural technique for correction of congenitally prominent ears. Plas. Reconstr. Surg., 32: $509,1963$.

15- Mustarde J.C.: The correction of prominent ears using simple mattress sutures. Br. J. Plast. Surg., 16: 170, 1963.

16- Pitanguy I., et al.: The treatment of prominent ears: A 25year survey of the island technique. Aesthetic. Plast. Surg., 11 (2): 87-93, 1987.

17- Weerda H.: Remarks about otoplasty and avulsion of the auricle. Laryngo-Rhino-Otol., 58 (3): 242-251, 1979. 